\title{
Accumulation of Azelaic Acid in Xylella fastidiosa-Infected Olive Trees: A Mobile Metabolite for Health Screening
}

\author{
Francesca Nicolì, Carmine Negro, Eliana Nutricati, ${ }^{\dagger}$ Marzia Vergine, Alessio Aprile, Erika Sabella, Gina Damiano, \\ Luigi De Bellis, and Andrea Luvisi
}

Department of Biological and Environmental Sciences and Technologies, University of Salento, Lecce, Italy. Accepted for publication 14 November 2018.

\begin{abstract}
Monitoring Xylella fastidiosa is critical for eradicating or at least containing this harmful pathogen. New low-cost and rapid methods for early detection capability are very much needed. Metabolomics may play a key role in diagnosis; in fact, mobile metabolites could avoid errors in sampling due to erratically distributed pathogens. Of the various different mobile signals, we studied dicarboxylic azelaic acid (AzA) which is a key molecule for biotic stress plant response but has not yet been associated with pathogens in olive trees. We found that infected Olea europaea L. plants of cultivars Cellina di Nardò (susceptible to X. fastidiosa) and Leccino (resistant to the pathogen) showed an increase in AzA accumulation in leaf petioles and in sprigs by approximately seven- and sixfold, respectively, compared with plants negative to $X$. fastidiosa or affected by other pathogens. No statistically significant variation was found between the $X$. fastidiosa population level and the amount of AzA in either of the plant tissues, suggesting that AzA accumulation was almost independent of the amount of pathogen in the sample. Furthermore, the association of AzA with $X$. fastidiosa seemed to be reliable for samples judged

as potentially false-negative by quantitative polymerase chain reaction (cycle threshold $\left[\mathrm{C}_{\mathrm{t}}\right]>33$ ), considering both the absolute value of AzA concentration and the values normalized on negative samples, which diverged significantly from control plants. The accumulation of AzA in infected plants was partially supported by the differential expression of two genes (named OeLTP1 and OeLTP2) encoding lipid transport proteins (LTPs), which shared a specific domain with the LTPs involved in AzA activity in systemic acquired resistance in other plant species. The expression level of OeLTP1 and OeLTP2 in petiole samples showed significant upregulation in samples positive to $X$. fastidios $a$ of both cultivars, with higher expression levels in positive samples of Cellina di Nardò compared with Leccino, whereas the two transcripts had a low expression level $\left(C_{t}>40\right)$ in negative samples of the susceptible cultivar. Although the results derived from the quantification of AzA cannot confirm the presence of the erratically distributed $X$. fastidiosa, which can be definitively assessed by traditional methods, we believe they represent a fast and cheap screening method for large-scale monitoring.
\end{abstract}

The spread of Xylella fastidiosa is reaching a worldwide scale, with a worrisome distribution in Europe (Almeida 2016; Stokstad 2015). In order to eradicate or at least contain this pathogen, monitoring is essential (Parnell et al. 2012) and involves finding novel methods for early detection (Zarco-Tejada et al. 2018), which are low cost and easy to execute (Chiriacò et al. 2018). In addition to the crucial role of traditional diagnostic tests for the verification of $X$. fastidiosa (i.e., molecular or immunoenzymatic tests), promising methods such as the analysis of volatile organic compounds are being developed to detect the disease before that it reaches the levels that can be detected by traditional methods. Such a new approach could be achieved by identifying the early plant-pathogen interaction mechanisms which can be highlighted by the analysis of biomarkers that are induced or altered in the host such as transcripts, proteins, and volatiles (Martinelli et al. 2015).

In addition to using biochemical markers as an early detection tool, such a strategy is low cost and rapidly applied. This is particularly useful for pathogens that require large-scale monitoring such as $X$. fastidiosa subsp. pauca strain CoDiRO (derived from the Italian name of the disease, "complesso del disseccamento rapido dell'olivo"), a bacterium associated with the olive quick decline syndrome (OQDS). The De Donno strain, derived from ST53 isolates retrieved from OQDS-affected plants, was recently sequenced (Giampetruzzi et al. 2017). This serious plant disease is destroying olive crops in Salento (Apulia, southern Italy) but also affects many

†Corresponding author: Eliana Nutricati; E-mail: eliana.nutricati@unisalento.it

*The $\boldsymbol{e}$-Xtra logo stands for "electronic extra" and indicates that one supplementary table is published online.

(c) 2019 The American Phytopathological Society other species (Luvisi et al. 2017b; Martelli 2016; Saponari et al. 2013), as well as olive trees in Brazil (Coletta-Filho et al. 2016, 2017).

The identification of a resistant olive cultivar (i.e., Leccino) would provide a more useful resource than the susceptible ones commonly grown in Salento (i.e., Cellina di Nardò) (Martelli 2016; Giampetruzzi et al. 2016; Saponari et al. 2017). Transcriptome profiling indicates differences in gene expression according to cultivar and health status (Giampetruzzi et al. 2016), and metabolic profiling (Luvisi et al. 2017a; Sabella et al. 2018) suggests the potential role of biochemicals in host-pathogen interactions or their use as biomarkers.

New developments in metabolomics are promising to elucidate the complex mechanism of plant-biotic interactions (Tenenboim and Brotman 2016), which may play a role for diagnostic purposes; in particular, whether they are related to mobile metabolites that could overcome some limits of traditional tests (i.e., the sampling of infected material due to erratically distributed pathogens).

Because plants lack mobility and, thus, are not able to avoid exposure to environmental stresses, they have evolved both constitutive and inducible means to respond to many abiotic and biotic stresses. For example, the remodeling of membrane fluidity and some of its components, such as fatty acids (FAs), contributes to inducible stress resistance (Upchurch 2008) and could be used for the early detection of pathogens (Walley et al. 2013). In fact, the enzymatic and nonenzymatic cleavage of FAs within a plant produces a pool of chemicals that can provide specific information about the source of stress - which is generally biotic - that the plant is encountering (Zoeller et al. 2012). One of these chemicals is azelaic acid (AzA), a dicarboxylic acid, generated by the hydrolysis of C18 FAs oleic acid (18:1) or its unsaturated derivatives, linoleic acid (18:2) and linolenic acid (18:3), which carry a double bond at carbon 9 whose biosynthesis pathway is largely unknown (Shine et al. in press; Yu et al. 2013). AzA is a mobile metabolite of the 
plant that confers local and systemic acquired resistance (SAR). It is also a signal against infection due to the pathogenic attack (Jung et al. 2009). Like many of the chemical SAR inducers, AzA requires a nonspecific lipid transfer protein (LTP) for its activity (Shine et al. in press). Because these FAs are essential for plant survival and they function redundantly in AzA biosynthesis, it is difficult to understand which plants do not contain AzA; however, its amount increases enormously as a result of the attack by pathogens (Ádám et al. 2018; Camañes et al. 2015; Nagy et al. 2017).

Because curative methods for the control of $X$. fastidios $a$ are not yet available, being able to identify the secondary metabolites involved in plant disease resistance and tolerance (Maddox et al. 2010) along with the mobile biochemical markers would be extremely useful as possible strategies for disease monitoring. However, to our knowledge, although AzA has been described in olive oil (Elkacmi et al. 2016; Godard et al. 2013), it has not been associated with the health status of Olea europaea L., regardless of the presence of other pathogens. Observations of the phenolic fraction of extra virgin olive oil produced from olive groves infected by $X$. fastidiosa indicated the presence of a significative amount of the metabolite AzA (data unpublished), suggesting further investigations in plant tissues infected by the pathogen. Thus, to better understand the interactions between the erratically distributed $X$. fastidios $a$ and olive trees and how they can affect a mobile metabolite such as AzA in naturally infected conditions, we investigated the presence of this chemical in petioles or sprigs of two cultivars previously defined as resistant or susceptible to $X$. fastidiosa (Leccino and Cellina di Nardò, respectively) (Saponari et al. 2017). Furthermore, two putative LTP genes that have been described for $O$. europaea var. sylvestris (GenBank accession numbers XM_023037740.1 and XM_023009062.1), likely related to the AzA activity, were isolated and their expression was evaluated.

\section{MATERIALS AND METHODS}

Plant material and experimental design. In order to limit the potential effects of plant growth or nutrient or water stress in the host-pathogen interaction, sampling was carried out during winter in orchards located in Lecce (Apulia, Southern Italy), on olive trees of Cellina di Nardò and Leccino. Selected plants ( 25 to 35 years old) had received the same agronomic practices (including insect control) over the previous 3 years, and phytosanitary treatments had been carried out by the farmers according to EU Decision 2015/789.

In order to avoid possible effects of different levels of water availability on the phenolic content among trees (Alagna et al. 2012; Machado et al. 2013), tree water status was assessed by $\Psi$ w measured 2 weeks before sampling, using a pressure chamber (Servili et al. 2007). No additional irrigation was considered necessary.

We evaluated the presence and the accumulation of AzA in petioles and sprigs ( 1 year old) in relation to (i) cultivar and health status of the plants (in terms of being positive or negative to $X$. fastidiosa or other pathogens) and (ii) level of infection of $X$. fastidiosa. A further trial was carried out to estimate the reliability of AzA as a biochemical marker. To evaluate AzA in relation to the cultivar and the health status, samples were collected from $X$. fastidiosa-positive trees ( $X f$-p, 10 naturally infected plants/ cultivar); $X$. fastidiosa-negative trees, $(X f$-n, 10 plants/cultivar); and $X$. fastidiosa-negative and pathogen-controlled trees $(X f$-pc, 10 plants/cultivar), in which no symptoms due to other pathogens were observed (asymptomatic plants) and plants were negative to specific tests. The presence of $X$. fastidiosa $(X f$-p) was assessed by real-time polymerase chain reaction (PCR) (Harper et al. 2010).

In both $X f$-p and $X f$-n samples, plants were monitored and tested for some of the most common pathogens in addition to $X$. fastidiosa, checking for symptoms caused by natural infection of Colletotrichum gloeosporioides, Mycocentrospora cladosporioides, Spilocaea oleagina, and Pseudomonas savastanoi pv. savastanoi. Symptoms of each pathogen were observed for each $X f$-p and $X f$-n tree during the 12 months before sampling. The presence of symptoms was scored using a severity scale of 1 to 3 , where $0=$ symptomless, $1=$ symptoms on a few branches $(\leq 5), 2=$ symptoms on several branches $(>5)$, and $3=$ symptoms uniformly distributed throughout the canopy. Plants were selected according to higher severity (3) for at least two pathogens (most frequently, S. oleagina and $P$. savastanoi pv. savastanoi).

Diagnostic tests (real-time PCR) were carried out on leaves or woody chips, according to protocols reported in the literature, for Verticillium dahliae (Bilodeau et al. 2012); Colletotrichum spp., C. acutatum, and C. gloeosporioides (Garrido et al. 2009); Phaeomoniella chlamydospora (Martín et al. 2012); Phaeoacremonium aleophilum and P. parasiticum (Aroca et al. 2008; Carlucci et al. 2015); Botryosphaeria dothidea (Romanazzi et al. 2009); Diplodia seriata (Martín et al. 2014); and Phytophthora spp. (Drenth et al. 2006) but $X f$-p and $X f$-n trees were negative to every test, apart from C. gloeosporioides. Thus, we concluded that $X f$-p and $X f$-n trees mainly differ in terms of the presence or absence $X$. fastidiosa. Conversely, $X f$-pc trees, in addition to not showing symptoms related to pathogens, were negative to all real-time PCR tests.

To evaluate the accumulation of AzA in relation to the infection levels, $X f$-p samples were assayed by real-time PCR and the relative cycle threshold $\left(C_{t}\right)$ was registered. The samples of both tissues were divided into five infection levels (five $\mathrm{C}_{\mathrm{t}}$ ranges: 22 to 24,25 to 27,28 to 30,31 to 33 , and $>33$; five trees per each infection level). The relative amount of AzA was calculated for samples belonging to each level.

To estimate the reliability of AzA as a biochemical marker of infection, two further tests were carried out. The first test aimed to estimate the sensitivity of AzA in samples collected from trees with a low level of infection which can lead to false-negative results $\left(C_{t}>\right.$ 33). $X f$-p and $X f$-n samples (leaves) were collected in spring from three different plants of Leccino ( $X f$-p 1,2, and 3 and $X f$-n 1, 2, and 3 ), a resistant cultivar that may have a negative impact on diagnostic sensitivity due to the erratic distribution of $X$. fastidiosa. Each $X f$-p sample was divided in two subsamples for AzA quantification and real-time PCR assay. Three biological replications were carried out (tests 1, 2, and 3). For each test and $X f$-p sample, the ratio (R) of AzA accumulation was calculated as the concentration of AzA in $X f-\mathrm{p}_{(\mathrm{n})}$ (expressed as micrograms per gram dry weight) over the concentration of AzA in $X f$-n (mean data obtained from three $X f$-n samples). A second test estimated the robustness of AzA analysis, calculating $R$ in $X f$-p samples (leaves) collected from plants grown with different water management (summer sampling on the Adriatic coast within irrigated or nonirrigated orchards), in geographic areas (summer sampling in nonirrigated orchards on the Adriatic coast or Ionic coast), or sampled in different seasons (winter or summer sampling in nonirrigated orchards on the Adriatic coast). For each factor of variability, AzA accumulation was quantified in five $X f$-p plants (chosen at random within the same orchard), calculating $\mathrm{R}$ regarding AzA concentration in irrigated $X f$-n (mean data obtained from three $X f$-n samples) $\left(\mathrm{R}_{\mathrm{W}}\right)$ or nonirrigated $X f$-n $\left(\mathrm{R}_{\mathrm{NW}}\right)$.

DNA extraction and real-time PCR. In total, 25 leaves were collected from six branches per plant in order to verify the presence of $X$. fastidiosa in olive tree samples. Petioles and basal portions of leaf blades from each sample were cut with a sterile scalpel. Plant tissue from each sample (approximately $1.0 \mathrm{~g}$ of leaf petioles) was transferred into an extraction bag (BIOREBA) and $4 \mathrm{ml}$ of extraction buffer (0.2 M Tris-HCl [pH 9], 0.4 M LiCl, and $25 \mathrm{mM}$ EDTA) was added. Samples were homogenized using a semiautomatic homogenizer (Homex 6; BIOREBA) at 50\% maximum speed. DNA was extracted according to Edwards et al. (1991), with some modifications, where the DNA solution was first extracted with a phenolchloroform-isoamyl alcohol $(25: 24: 1)$ mixture to remove protein contaminants, then precipitated with $100 \%$ isopropanol.

The isolated DNA was used as a template for $X$. fastidios $a$ detection by the TaqMan real-time PCR protocol with XF-F/R primers and an XF-P probe (Harper et al. 2010). Reactions were performed in a realtime thermal cycler (ABI PRISM 7900HT, Applied Biosystems). 
Each reaction consisted of $5 \mu \mathrm{l}$ from a 20 -ng $\mu \mathrm{l}^{-1}$ dilution of DNA extracted from leaf petioles, $12.5 \mu \mathrm{l}$ of Master Mix (Applied Biosystems), $400 \mathrm{nM}$ forward and reverse primers, $200 \mathrm{nM}$ TaqMan probe, and ultrapure DNase/RNase-free water (Carlo Erba Reagents) in a total volume of $25 \mu \mathrm{l}$. The following cycling conditions were implemented: an initial denaturation step at $95^{\circ} \mathrm{C}$ for $10 \mathrm{~min}$, followed by 40 cycles of $95^{\circ} \mathrm{C}$ for $15 \mathrm{~s}$ and $60^{\circ} \mathrm{C}$ for $1 \mathrm{~min}$. The final dissociation was at $95^{\circ} \mathrm{C}$ for $15 \mathrm{~s}, 60^{\circ} \mathrm{C}$ for $30 \mathrm{~s}$, and $95^{\circ} \mathrm{C}$ for $15 \mathrm{~s}$.

AzA extraction and quantification. Approximately $0.30 \mathrm{~g}$ of leaf petioles and relative sprigs was transferred into an extraction bag (BIOREBA) and $5 \mathrm{ml}$ of extraction buffer, $\mathrm{pH} 2.8$ (methanolwater-formic acid, 60:39.9:0.1) was added. A semiautomatic homogenizer (Homex 6) was used at $50 \%$ maximum speed. The extracts were centrifuged at $5,000 \times g$ for $3 \mathrm{~min}$, filtered through a 0.20 - $\mu \mathrm{m}$ syringe filter, and then analyzed. AzA was characterized using an Agilent 1200 liquid chromatography system (Agilent Technologies) equipped with a standard autosampler (Sabella et al. 2018). The high-performance liquid chromatography (HPLC) column was an Agilent Extend-C18 (1.8 $\mu \mathrm{m}, 2.1$ by $50 \mathrm{~mm})$. Separation was carried out at $40^{\circ} \mathrm{C}$ with a gradient elution program at a flow rate of $0.5 \mathrm{ml} / \mathrm{min}$. The mobile phases used were water plus $0.1 \%$ formic acid (A) and acetonitrile (B). We used a multistep linear gradient: $0 \mathrm{~min}, 1 \% \mathrm{~B} ; 13 \mathrm{~min}, 25 \% \mathrm{~B} ; 19 \mathrm{~min}, 40 \% \mathrm{~B}$; and $21 \mathrm{~min}, 90 \% \mathrm{~B}$. The initial conditions were maintained for $5 \mathrm{~min}$. The HPLC system was coupled to an Agilent 6320 time-of-flight (TOF) mass spectrometer, equipped with a dual electrospray ionization (ESI) interface (Agilent Technologies) operating in negative ion mode using a capillary voltage of $+3.5 \mathrm{kV}$. The other optimum values of the ESI-TOF-mass spectrometry (MS) parameters were drying gas temperature, $\left(\mathrm{N}_{2}\right), 300^{\circ} \mathrm{C}$; drying gas flow, 12 liters $/ \mathrm{min}$; and nebulizing gas pressure, $40 \mathrm{psig}$. A mass range of 50 to $1,700 \mathrm{~m} / \mathrm{z}$ was used for detection. The total ion chromatograms of each peak were measured with an ISO Pump (Agilent G1310B) using a dual nebulizer ESI source that introduces a low flow $\left(20 \mu \mathrm{l} \cdot \mathrm{min}^{-1}\right)$ of a calibration solution. This solution contained the internal reference masses at $\mathrm{m} / \mathrm{z}$ 112.9856, 301.9981, 601.9790, and 1,033.9881, in negative-ion mode. Mass Hunter (Agilent Technologies) was used to process the mass data of the molecular ions.

A standard calibration graph for the quantification of the AzA of olive leaves and sprigs was prepared using a commercial standard (AzA, 98\%; ACROS). The standard was dissolved in a mixture of methanol and water $(60: 40, \mathrm{vol} / \mathrm{vol})$ and diluted in water plus $0.1 \%$ formic acid. The recovery was used to evaluate the accuracy of the method. Known amounts of standard were added to $0.30 \mathrm{~g}$ of the samples. The method described above was then used again for extracting and analyzing the mixture.

The tests were carried out in three replicates. Recovery (Rec) was calculated as $\operatorname{Rec}=100\left(\mathrm{C}_{\text {found }}-\mathrm{C}_{\text {initial }}\right) / \mathrm{C}_{\text {added }}$ for each compound, where $\mathrm{C}_{\text {found }}=$ measured concentration in the fortified sample, $\mathrm{C}_{\text {initial }}=$ initial concentration in the sample, and $\mathrm{C}_{\text {added }}=$ concentration in the standard solution used. An amount of standard that was five times higher than the endogenous concentration was added to the milled fresh leaves and sprig methanol solution in order to assess the analytical recoveries. Data were presented as analytical recovery (percent).

To reveal any variability in the extraction method, the procedure was repeated four times on the same pool of leaves and sprigs, with no statistically relevant difference being found among replicates.
The limit of quantification (LOQ) was determined as the signal-tonoise ratio of 10:1, and the limit of detection (LOD) was determined as the signal-to-noise ratio of 3:1. Intraday and interday precision was performed to assess the repeatability of the method, expressed by the relative standard deviation (RSD). A sprig extract and olive leaf were injected $(n=5)$ on the same day (intraday precision) for three consecutive days (interday precision, $n=15$ ). The amount of AzA in leaves or sprig was expressed as micrograms per gram dry weight.

RNA extraction, cDNA synthesis, and isolation of $L T P$ genes from $\boldsymbol{O}$. europaea. Petioles from the samples $X f$-p and $X f$-n, 10 for each cultivar, were collected and frozen in liquid nitrogen. Total RNA was isolated from approximately $0.1 \mathrm{~g}$ of frozen petioles (per sample), and was performed with the TRIzol reagent (Invitrogen) according to the manufacturer's instructions. Total RNA was used to synthesize cDNA using a TaqMan Reverse Transcription Reagents kit (Applied Biosystems). To obtain fulllength cDNAs coding putative LTPs in Cellina di Nardò and Leccino trees, primers were designed based on the sequences of LTP genes from O. europaea var. sylvestris (GenBank accession numbers XM_023037740.1 and XM_023009062.1) and were used to amplify the cDNA fragment using PCR (Supplementary Table $\mathrm{S} 1$ ). All products were cloned into the pCR4TOPO vector (Life Technologies) according to the manufacturer's instructions, and both strands were sequenced. Full-length cDNAs were obtained which shared a high homology to O. europaea var. sylvestris genes, nonspecific LTP 1-like (XM_023037740.1) and nonspecific LTP 3-like isoform X2 (XM_023009062.1), respectively.

Bioinformatic and phylogenetic analysis. The coding sequence and relative amino acid sequences of Arabidopsis AtDIRI and AtLTP1 were retrieved from the Arabidopsis Information Resource website (https://www.arabidopsis.org/). The sequences of AtDIRl and AtLTPl genes were used as queries to search for homologs in the O. europaea in the National Center for Biotechnology Information (NCBI) database (https://www.ncbi.nlm.nih.gov), using BLAST. The predicted protein information was conducted using EXPASY (https://www.expasy.org/resources). Signal peptides were revealed using the SignalP 3.0 prediction server at www.cbs.dtu.dk/ services/SignalP. Conserved domains were identified using Conserved Domain Database (CDD; https://www.ncbi.nlm.nih.gov/cdd/).

To study the phylogenetic relationship of olive tree LTPs with other plant orthologs, full-length amino acid sequences were aligned with ClustalW (https://www.ebi.ac.uk/Tools/msa/clustalw2). A phylogenetic tree based on LTP family members was constructed through Molecular Evolutionary Genetics Analysis, version 7.0 (Kumar et al. 2016) using the neighbor-joining method. The analysis involved 13 amino acid sequences. All positions containing gaps and missing data were eliminated. The bootstrap consensus tree inferred from 100 replicates is taken to represent the evolutionary history of the taxa analyzed. Branches corresponding to partitions reproduced in less than $50 \%$ bootstrap replicates were collapsed. The evolutionary distances were computed using the JTT matrix-based method and are in units of the number of amino acid substitutions per site.

Analysis of genes expression. Real-time quantitative, reversetranscription (RT)-PCR was performed with a Power SYBR Green RT-PCR Master mix (Applied Biosystems). Real-time PCR conditions were: $50^{\circ} \mathrm{C}$ for $2 \mathrm{~min}, 95^{\circ} \mathrm{C}$ for $10 \mathrm{~min}$, followed by 40 cycles of $95^{\circ} \mathrm{C}$ for $15 \mathrm{~s}$ and $60^{\circ} \mathrm{C}$ for $1 \mathrm{~min}$. The list of primers is provided in Table 1. All PCRs were performed in triplicate. For each sample, a $C_{t}$

TABLE 1. Primers used for real-time polymerase chain reaction to evaluate the OeLTP1 and OeLTP2 expression in Olea europaea 'Cellina di Nardò' and 'Leccino'

\begin{tabular}{lll}
\hline Gene symbol & \multicolumn{1}{c}{ Function } & \multicolumn{1}{c}{ Primer sequence $\left(5^{\prime}\right.$ to $\left.3^{\prime}\right)$} \\
\hline$U B Q$ & Polyubiquitin OUB2 mRNA & GGTGGCCTCTAAATGTTCTTCTACTG \\
OeLTP1 & Nonspecific lipid transfer protein like 1 & CACACAGACTTCATTAGAAAGACAATCA \\
OeLTP2 & GTCCATCTGCTACTGCCTGAAA \\
& & CTTGCTGTAGTTGATGCCCTTAAA \\
\hline
\end{tabular}


value was calculated from the amplification curves. The fold change in relative gene expression was determined as $\mathrm{FC}=2^{-\Delta \Delta \mathrm{Ct}}$, where $\Delta \Delta$ $C_{t}=\left(C_{t}\right.$ target gene $-C_{t}$ reference gene $)$ infected sample $-\left(C_{t}\right.$ target gene $-C_{t}$ reference gene) healthy sample.

The $C_{t}$ data are expressed as an average of the 10 samples. Amplifications that do not show any amplification curve within 40 cycles were considered out of detection range and marked as not detectable. For each gene, the relative amount of calculated mRNA was normalized to the level of the reference gene polyubiquitin (UBQ; AF429430). It was selected as a suitable reference gene because it was the most stable transcript in healthy and infected olive tree cultivars (Giampetruzzi et al. 2016).

Statistical analysis. The open source software R version 3.5.0 (R Foundation for Statistical Analysis) was used for all data analyses. After evaluating the normal distribution of variance among data (Shapiro's test), one-way or two-way analysis of variance (ANOVA) was performed. Pairwise comparisons ( $t$ test), were applied ( $P$ values $<0.05$ were considered to be significant) to test the statistical significance of the AzA contents found among samples. Statistical significances were recorded (where $*$, **, and *** indicate $P<0.05,0.01$, and 0.001 , respectively).

\section{RESULTS}

AzA identification. The AzA compound characterized by HPLC ESI-TOF is reported in Table 2, along with its retention time, $\mathrm{m} / \mathrm{z}$ experimental and calculated, difference ( $\mathrm{ppm}$ ) between the

TABLE 2. Characterization of azelaic acid detected in olive leaf and sprig extract by HPLC ESI-TOF (ion M-H) ${ }^{-a}$

\begin{tabular}{lcccccc}
\hline Compound & $\begin{array}{c}\mathrm{RT} \\
(\mathrm{min})\end{array}$ & $\begin{array}{c}(\mathrm{M}-\mathrm{H})^{-} \\
\text {Exp }\end{array}$ & $\mathrm{m} / \mathrm{z}$ Exp & $\mathrm{m} / \mathrm{z} \mathrm{Clc}$ & $\begin{array}{c}\text { Diff. } \\
(\mathrm{ppm})^{\mathrm{b}}\end{array}$ & Score $^{\mathrm{c}}$ \\
\hline $\begin{array}{l}\text { Azelaic } \\
\text { acid }\end{array}$ & 7.0734 & $\mathrm{C}_{9} \mathrm{H}_{15} \mathrm{O}_{4}$ & 187.0976 & 187.0973 & 1.76 & 99.44 \\
\hline
\end{tabular}

${ }^{\mathrm{a}} \mathrm{RT}=$ retention time, $\mathrm{Exp}=$ experimental, and $\mathrm{Clc}=$ calculated.

b Relative difference: the difference between the observed mass and the theoretical mass of the compound (ppm).

c Isotopic abundance distribution match: a measure of the probability that the distribution of isotope abundance ratios calculated for the formula matches the measured data. observed mass and the theoretical mass, isotopic abundance distribution match, and molecular formula generated by the software for the detected deprotonated molecule. Peaks were identified by comparing both migration time and MS spectral data obtained from samples with the authentic analytical standard. The calibration plot indicated a good correlation between peak area and analyte concentration and the regression coefficient was higher than 0.999 . LOD had a value of $0.008 \mu \mathrm{g} \cdot \mathrm{ml}^{-1}$, while LOQ was $0.08 \mu \mathrm{g} \cdot \mathrm{ml}^{-1}$. The intraday repeatability of the peak area, expressed by RSD, was $0.85 \%$, whereas the interday repeatability was $1.1 \%$. The parameters of the calibration curve are summarized in Table 3.

Evaluation of accumulation of $\mathrm{AzA}$ according to cultivar, health status and level of infection. Amounts of AzA in $X f$-p, $X f$-n, and $X f$-pc trees of Cellina di Nardò and Leccino are reported in Table 4. Two-way ANOVA showed that the AzA accumulation was influenced by the health status of the sample. Indeed, a high level of significance for "health status" was observed in both the petioles $(P<0.001)$ and sprigs $(P<0.001)$. Genotype was a factor that did not determine significant differences in the amount of AzA in either of the tissues (petioles or sprigs). Furthermore, the analysis of the health status-genotype variance was not significant to explain variations in the AzA accumulation in both tissues. Additionally, no statistically significant variation in leaf petioles or sprigs in the AzA amount was observed between either kind of negative sample ( $X f$-n and $X f$-pc) of the two cultivars. Therefore, $X$. fastidiosa infection was associated with a statistically significant increase in AzA in both genotypes. In fact, X. fastidiosapositive samples belonging to Cellina di Nardò and Leccino showed an increase of AzA in leaf petioles (approximately sevenfold) and in sprigs (approximately sixfold), regardless of the presence of other pathogens.

Subsequently, because the accumulation of AzA showed a significant variation only in relation to the PCR-confirmed health status ( $X f$-p or $X f$-n/ $X f$-pc) and not to the genotype, the samples were analyzed in relation to the $X$. fastidios $a$ population level, evaluated by real-time PCR and relative $C_{t}$ (Table 5). No statistically significant variation was found between the $X$. fastidiosa population level (expressed as $C_{t}$ ) and the amount of AzA in either of the plant tissues. In particular, we found a high amount of AzA even in samples collected from $X f$-p trees that showed a $\mathrm{C}_{\mathrm{t}}>33$.

TABLE 3. Parameters of calibration curve, limit of detection (LOD), limit of quantification (LOQ), relative standard deviation (RSD), and recovery for the highperformance liquid chromatography method validation of azelaic acid assay

\begin{tabular}{lccccccc}
\hline & Slope & Intercept & $r^{2}$ & LOD $\left(\mu \mathrm{g} \mathrm{ml} l^{-1}\right)$ & LOQ $\left(\mu \mathrm{g} \mathrm{ml}^{-1}\right)$ & RSD $(\%)$ & Recovery $(\mathrm{mean} \%)$ \\
\hline Standard azelaic acid & $6.46 \mathrm{E}+04$ & $2.54 \mathrm{E}+03$ & 0.999 & 0.008 & 0.08 & 0.85 & 85 \\
\hline
\end{tabular}

TABLE 4. Amount of azelaic acid retrieved in leaves or sprigs of Xylella fastidiosa-positive or -negative samples ${ }^{\mathrm{a}}$

\begin{tabular}{lccc}
\hline Cultivar, health status $^{\mathrm{b}}$ & $\mathrm{C}_{\mathrm{t}}$ & Leaf $\left(\mu \mathrm{g} \mathrm{g}^{-1}\right.$ dry weight $)$ & Sprig $\left(\mu \mathrm{g} \mathrm{g}^{-1}\right.$ dry weight $)$ \\
\hline Cellina di Nardò & & & \\
$X f-\mathrm{p}$ & $22.8-29.9$ & $13.13 \pm 2.70$ & $8.57 \pm 2.65$ \\
$X f-\mathrm{n}$ & $\ldots$ & $1.15 \pm 0.75$ & $0.61 \pm 0.59$ \\
$X f-\mathrm{pc}$ & $\ldots$ & $2.15 \pm 0.54$ & $2.00 \pm 1.01$ \\
Leccino & $26.5-31.7$ & $14.92 \pm 2.93$ & $10.52 \pm 3.37$ \\
$X f-\mathrm{p}$ & $\ldots$ & $2.28 \pm 1.78$ & $0.92 \pm 1.05$ \\
$X f-\mathrm{n}$ & $\ldots$ & $1.97 \pm 0.89$ & $2.49 \pm 0.60$ \\
$X f$-pc & $\ldots$ & $* * *$ & $* * *$ \\
Significance & $\ldots$ & $\mathrm{ns}$ & $\mathrm{ns}$ \\
Health status & $\ldots$ & $\mathrm{ns}$ & $\mathrm{ns}$ \\
Genotype & $\ldots$ & $\mathrm{ns}$ & \\
Health status $\times$ genotype & & & \\
\hline
\end{tabular}

a Samples are classified according to the cultivar (Cellina di Nardò or Leccino). Mean real-time polymerase chain reaction cycle thresholds $\left(\mathrm{C}_{\mathrm{t}}\right)$ are reported for positive samples; negative samples are classified according to the presence or absence of other pathogens. Two-way analysis of variance was carried out to evaluate statistical differences and interaction among factors (genotype and health status); *** indicates $P<0.001$ and ns $=$ not significant.

${ }^{\mathrm{b}} X f$ - $\mathrm{p}=X$. fastidiosa-positive sample, with other pathogens occurring; $X f$ - $\mathrm{n}=X$. fastidiosa-negative sample, with other pathogens occurring; and $X f$-pc $=X$. fastidiosa-negative sample, without other pathogens occurring. 
Evaluation of AzA as a biochemical marker of infection. In addition to the remarkable difference observed in the AzA accumulation between positive and negative $X$. fastidiosa samples, absolute values may not have taken into account that biochemical parameters can be influenced by the period of sampling and reproducibility of HPLC analysis. Thus, the evaluation of AzA accumulation was normalized, considering negative control plants as the baseline (mean data from samples collected from three $X f$-n trees) and calculating the R of AzA to compare with standard realtime PCR values (Table 6). All computed ratios showed values $>6.6$, indicating that the amount of AzA in plants infected by $X$. fastidiosa was significantly higher than the concentration observed in negative plants. High ratios were also observed for two samples (test $1, X f$-p 1 and $X f$-p 3), in which samples judged as being potentially false negative $\left(C_{t}>33\right)$ showed a ratio of 9.7 and 17.9.

With regard to tests in different growth conditions, all computed ratios of $X f$-p showed values $>4.9$, regardless of the $X f$-n chosen (irrigated or nonirrigated) (Table 7). Thus, the amount of AzA in positive samples to real-time PCR seems to be very high compared with those found in $X$. fastidiosa-negative plants, regardless of the sampling season, geographic area, or water management. Among all samples tested, the amount of AzA detected in $X f$-n samples did not exceed $4 \mu \mathrm{g} \mathrm{g}^{-1}$ dry weight, whereas the amount of AzA detected

TABLE 5. Amount of azelaic acid in leaves or sprig positive to Xylella

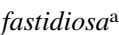

\begin{tabular}{lcc}
\hline Health status & Leaf $\left(\mu \mathrm{g} \mathrm{g}^{-1}\right.$ dry weight $)$ & Sprig $\left(\mu \mathrm{g} \mathrm{g}^{-1}\right.$ dry weight $)$ \\
\hline$X f-\mathrm{p}, \mathrm{C}_{\mathrm{t}}=22-24$ & $12.06 \pm 1.83$ & $7.31 \pm 0.60$ \\
$X f-\mathrm{p}, \mathrm{C}_{\mathrm{t}}=25-27$ & $13.28 \pm 2.17$ & $7.87 \pm 2.25$ \\
$X f-\mathrm{p}, \mathrm{C}_{\mathrm{t}}=28-30$ & $12.77 \pm 2.34$ & $8.94 \pm 2.78$ \\
$X f-\mathrm{p}, \mathrm{C}_{\mathrm{t}}=31-33$ & $15.86 \pm 3.00$ & $9.50 \pm 1.12$ \\
$X f-\mathrm{p}, \mathrm{C}_{\mathrm{t}}>33$ & $16.66 \pm 4.60$ & $10.63 \pm 1.06$ \\
Significance & $\mathrm{ns}$ & $\mathrm{ns}$ \\
\hline
\end{tabular}

a Positive samples are classified according to the real-time polymerase chain reaction cycle threshold $\left(\mathrm{C}_{\mathrm{t}}\right) . X f$ - $\mathrm{p}=X$. fastidiosa-positive sample and $\mathrm{ns}=$ not significant.

TABLE 6. Ratio (R) of the azelaic acid (AzA) amount in the positive sample $(X f$-p) and negative sample to Xylella fastidiosa (mean data obtained from three negative plants) ${ }^{\mathrm{a}}$

\begin{tabular}{|c|c|c|c|c|c|c|c|c|c|}
\hline \multirow[b]{2}{*}{ Test } & \multicolumn{3}{|c|}{$X f$-p 1} & \multicolumn{3}{|c|}{$X f$-p 2} & \multicolumn{3}{|c|}{$X f$-p 3} \\
\hline & AzA & $\mathrm{R}$ & $\mathrm{C}_{\mathrm{t}}$ & AzA & $\mathrm{R}$ & $\mathrm{C}_{\mathrm{t}}$ & AzA & $\mathrm{R}$ & $\mathrm{C}_{\mathrm{t}}$ \\
\hline Test 1 & 7.6 & 9.7 & 34.4 & 20.2 & 25.7 & 33.3 & 14.1 & 17.9 & 34.3 \\
\hline Test 2 & 4.7 & 6.6 & 32.8 & 24.8 & 35.1 & 26.2 & 18.8 & 26.5 & 26.5 \\
\hline Test 3 & 12.1 & 13.3 & 32.3 & 11.7 & 12.9 & 28.4 & 26.2 & 28.8 & 28.8 \\
\hline
\end{tabular}

a $X$. fastidiosa-positive $(X f$-p) samples (leaves) were collected from three different plants $(X f$-p 1, 2, and 3). Three tests are reported: AzA absolute value ( $\mu \mathrm{g} \mathrm{g}^{-1}$ dry weight), $\mathrm{R}$, and real-time polymerase chain reaction cycle threshold $\left(\mathrm{C}_{\mathrm{t}}\right)$ calculated for each $X f$-p sampled.

TABLE 7. Ratio (R) of the azelaic acid (AzA) amount in the positive sample $\left(X f\right.$-p) and negative sample $\left(X f\right.$-n) to Xylella fastidiosa $a^{\mathrm{a}}$

\begin{tabular}{|c|c|c|c|c|}
\hline Variables & $\mathrm{R}_{\mathrm{W}}$ & $\mathrm{R}_{\mathrm{NW}}$ & $\begin{array}{l}\text { AzA ( } \mu \mathrm{g} \mathrm{g}^{-1} \\
\text { dry weight) }\end{array}$ & $\mathrm{C}_{\mathrm{t}}(X f-\mathrm{p})$ \\
\hline \multicolumn{5}{|l|}{ Sampling season } \\
\hline Winter & 7.0 & 8.6 & 12.3 & 27.0 \\
\hline Summer & 4.9 & 13.9 & 6.3 & 24.8 \\
\hline \multicolumn{5}{|l|}{ Geographic area } \\
\hline Adriatic coast & 5.5 & 15.6 & 7.0 & 25.8 \\
\hline Ionic coast & 4.9 & 13.9 & 6.3 & 25.2 \\
\hline \multicolumn{5}{|l|}{ Water management } \\
\hline Irrigated orchard & 11.6 & 32.9 & 14.9 & 25.6 \\
\hline Nonirrigated orchard & 5.1 & 14.5 & 6.6 & 26.0 \\
\hline
\end{tabular}

in $X f$-p samples was not lower than approximately $12 \mu \mathrm{g} \mathrm{g} \mathrm{g}^{-1}$ dry weight in leaves. These results suggest that $R=3$ could be considered as a threshold value to consider samples as positive to $X$. fastidiosa. However, a remarkable variation in absolute values of AzA was observed, indicating that a pluriannual test is required to assess the role of factors involved in accumulation of AzA and to define a reliable threshold value.

Identification of $\boldsymbol{L T P}$ genes in $\boldsymbol{O}$. europaea. To identify O. europaea gene AZI from the Arabidopsis AzA-induced 1 (AZII) gene sequence, a search in NCBI databases was carried out, with no result. Subsequently, degenerate primers were designed on the conservative sequences of known plant $A Z I$ genes for RT-PCR analysis but no cDNA for the Olea AZI gene was found. Therefore, the expression of Olea LTP genes belonging to the same superfamily of $A Z I 1$ and defective in induced resistance (DIRI) was analyzed for their involvement in the transport in a mobile signal such as AzA (Safi et al. 2015).

Two genes coding LTP were isolated in leaf petioles of Leccino and Cellina di Nardò. The genes were designated as OeLTP1 and OeLTP2. They had significant homology with LTP1 and LTP2 genes retrieved in other plant species (Arabidopsis thaliana, Capsicum annuum, Hordeum vulgare, Nicotiana tabacum, and Oryza sativa). The OeLTP1 nucleotide sequence (GenBank accession number MH594116) is composed by 489 nucleotides (nt), whereas the OeLTP2 nucleotide sequence (GenBank accession number MH594117) is $383 \mathrm{nt}$ in length.

Gene expression analysis. The expression level of OeLTP1 and $O e L T P 2$ was evaluated in petiole samples that were positive and negative to $X$. fastidiosa in both cultivars (Table 8). In Leccino, a downregulation of both genes was observed in the $X$. fastidiosanegative samples. In particular, OeLTPl in $X f$-p samples showed a higher level of expression $\left(\mathrm{C}_{\mathrm{t}}=26.3\right)$ compared with $X f$-n $\left(\mathrm{C}_{\mathrm{t}}=\right.$ $27.8)$, corresponding to a fold change of $6.52 \pm 0.01$. Also, the level of expression of OeLTP2 was higher in positive $\left(\mathrm{C}_{\mathrm{t}}=31.8\right)$ than negative samples $\left(C_{t}=32.4\right)$, with an estimated fold change of 2.82 \pm 0.64 . For both genes, no expression was observed in up to 40 amplification cycles in $X f$-n of Cellina di Nardò (Table 8). The OeLTP1 and OeLTP 2 expression level in the positive samples was higher than in infected Leccino $\left(C_{t}=22.5\right.$ and $C_{t}=28.7$, respectively). Thus, both transcripts in the two cultivars analyzed were differentially expressed in relation to sample health status, and a higher-level expression was associated with samples positive to $X$. fastidiosa, regardless to the presence of the most common olive tree pathogens.

Structure and biochemistry of $O e$ LTP1 and $O e$ LTP2 protein. Bioinformatic analysis showed that the OeLTP1 and $O e$ LTP2 proteins are synthesized as precursors containing 26- and 27-amino-acid N-terminal signal peptides, respectively, whereas the mature proteins contained 90 residues. Conserved domains were predicted using NCBI CDD: OeLTP1 displays a hydrophobic cavity and both proteins containing eight conservative cysteine residues forming four disulfide bonds, with the general pattern

TABLE 8. Gene level expression of OeLTP1 and OeLTP2 in petiole samples of Leccino and Cellina di Nardò cultivars expressed as cycle threshold $\left(\mathrm{C}_{\mathrm{t}}\right)^{\mathrm{a}}$

\begin{tabular}{lccccc}
\hline & \multicolumn{4}{c}{ Genes level expression $\left(\mathrm{C}_{\mathrm{t}}\right)$} \\
\cline { 2 - 3 } \cline { 5 - 6 } Gene & \multicolumn{2}{c}{ Leccino } & & \multicolumn{2}{c}{ Cellina di Nardò } \\
\cline { 2 - 3 } \cline { 5 - 6 } OeLTP1 & $26.3 \pm 0.6$ & $27.8 \pm 0.4$ & & $22.5 \pm 2.7$ & n.d. $(>40)$ \\
OeLTP2 & $31.8 \pm 0.6$ & $32.4 \pm 0.3$ & & $28.7 \pm 0.8$ & n.d. $(>40)$ \\
\hline
\end{tabular}

${ }^{\text {a } X f}$ - $\mathrm{p}=X$. fastidiosa-positive sample, with other pathogens occurring and $X f$ $\mathrm{n}=X$. fastidiosa-negative sample, with other pathogens occurring. Resulting values are given and show a distinct expression profile for $X f$-p and $X f$-n cDNA, respectively. Amplifications that do not show any amplification curve within 40 cycles were considered out of detection range and marked as n.d. (not detectable). 
CXnCXnCCXnCxCxnCxnC (Fig. 1). Protein-protein BlastP and multiple-alignment analysis showed that the deduced amino acid sequences had a high similarity to LTP sequences from other plant species, suggesting that $O e \mathrm{LTP} 1$ and $O e \mathrm{LTP} 2$ belong to the LTP family.

In order to determine the phylogenetic position, the two amino acid sequences, lacking the divergent signal sequence, were compared with pepper, tobacco, cotton, barley, rice, tomato, and Arabidopsis LTP sequences. This analysis showed two main clades: $O e \mathrm{LTP} 1$ was grouped with $A t \mathrm{LTP} 1$ and $G h \mathrm{LTP}$, whereas $O e \mathrm{LTP} 2$ had a common origin with NtDIR1, AtDIR1, and other LTP2 proteins (Fig. 2).

\section{DISCUSSION}

Understanding plant-pathogen interactions is critical to improving integrated management strategies of diseases and for developing diagnostic tools based on specific biochemical markers. A key role is played by lipids and their derivatives and knowledge of their functions in plant-microbe interactions has increased through advances in highly sensitive analytical technologies (Siebers et al. 2016). Several studies about $X$. fastidiosa-host plant interaction have reported a significant variation in the amount of different phenolic compounds such as hydroxytyrosol glucoside, quinic acid, caftaric acid, and lignin in xylem tissues (Luvisi et al. 2017a; Sabella et al. 2018; Wallis and Chen 2012), and some of these compounds have been correlated with resistance to infection or showed in vitro antibacterial properties (Maddox et al. 2010). Conversely, few data are available about the potential role of lipidderivates in $X$. fastidiosa-host plant interaction, and our aim was to analyze in olive trees the correlation between the amount of one of these lipid derivatives, AzA, and a systemic pathogen such as $X$. fastidiosa. Previous studies in Arabidopsis have shown that AzA is a metabolite produced as a mobile molecule that signals infection due to the pathogenic attack and can also trigger systemic defenses (Kachroo and Robin 2013; Shah 2009; Yu et al. 2013).

We found a significant increase in AzA accumulation in olive trees of Cellina di Nardò and Leccino naturally infected by $X$. fastidiosa compared with $X f$-n plants (approximately six- to sevenfold), regardless of the tested tissues (leaf and sprig) or the presence of other pathogens. Furthermore, we found no significant difference with respect to susceptible cultivar or resistant cultivar in AzA accumulation. As reported by Jung et al. (2009) and Shah (2009), AzA may prime the resistance to infection and antibacterial activity against pathogens and significant AzA increase was observed in various plant-pathogen interactions such as Arabidopsis infected by Pseudomonas syringae (approximately sixfold increase) and Solanum lycopersicum infected by Botrytis cinerea or P. syringae (approximately fivefold increase) (Camañes et al. 2015; Jung et al. 2009). Because $X$. fastidiosa is an aggressive pathogen with systemic distribution in olive trees, the significant increase of AzA observed in both plant tissues and its recovery even in samples with low bacteria concentration could be explained by its role as a specific mobile signal produced after the activation of constitutive defenses during the systemic pathogen infection. To confirm this, we did not observe any correlation between the amount of AzA and level of infection, and a high amount of AzA was detected even in the samples potentially reported as being possible false negatives by real-time PCR, an event not uncommon for an erratically distributed pathogen such as $X$. fastidiosa. Furthermore, the low accumulation of AzA in $X f$-n trees infected by other pathogens underlines the putative specific response of AzA. We speculate that the monitored pathogens (Colletotrichum gloeosporioides, M. cladosporioides, Spilocaea oleagina, and $P$. savastanoi pv. savastanoi), even if uniformly distributed throughout the canopy, did not significantly trigger the production of AzA, probably because they are not systemically distributed in the whole plant and do not cause a severe stress condition such as $X$. fastidiosa infection.

Tests carried out in different seasons or geographical areas or under different water management conditions suggested how AzA concentration may vary, although its amount was remarkably higher in infected plants compared with healthy ones. Thus, the AzA accumulation, expressed as an absolute value or as a ratio, seems to be almost independent of the amount of pathogen in the sample,

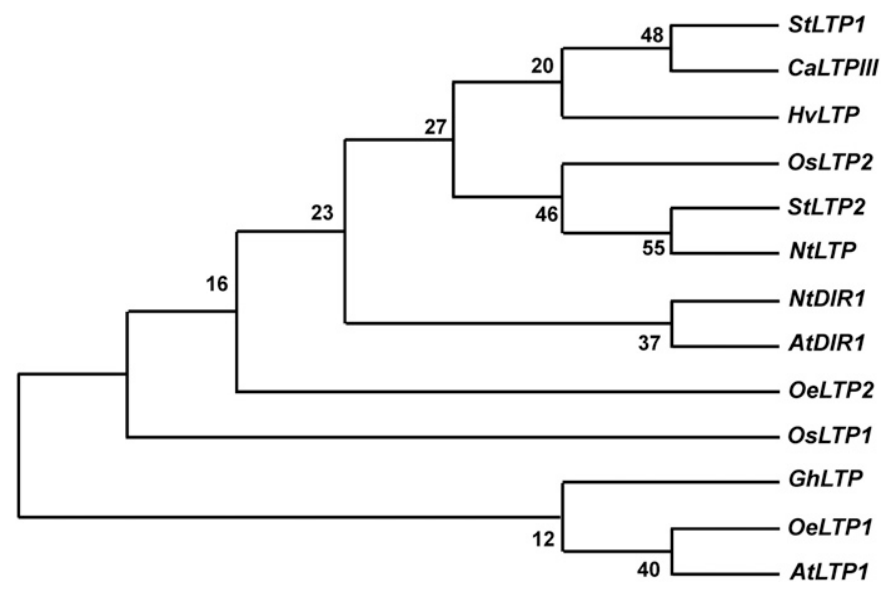

Fig. 2. Phylogenetic tree of $O e$ LTP1 and $O e$ LTP2 with other plants' characterized lipid transport protein (LTP). Sequence alignment was performed with ClustalW. The tree was constructed using the neighbor-joining method. Branches corresponding to partitions reproduced in $<50 \%$ of bootstrap replicates are collapsed. Percentages of replicates trees in which the associated taxa clustered together in the bootstrap test (100 replicates) are shown next to the branches. Evolutionary distances were computed using the JTT matrix-based method. All positions containing gaps and missing data were eliminated. Protein accession numbers are AtLTP1 (AEC09547.1), AtDIR1 (OAO90722.1), CaLTPIII (AF208834_1), HvLTP (CAA42832), NtDIR1 (XP_016480559.1), NtLTP(XP_009777694.1), GhLTP (Q43129.1), OsLTP1 (AAP92127.1), OsLTP2 (AAC50030.1), StLTP1 (NP001234074.1), and StLTP2 (NP001275625.1).

A

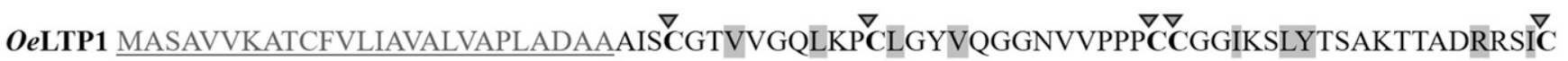
YČLKSLAGSFKGINYSKAAGLPGKČGVNIPYKIDPSTDČSK

B

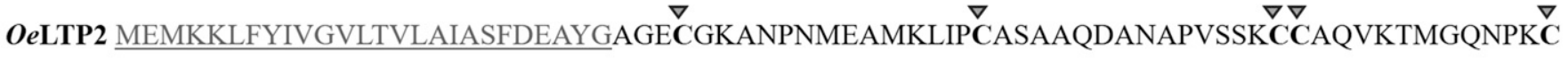

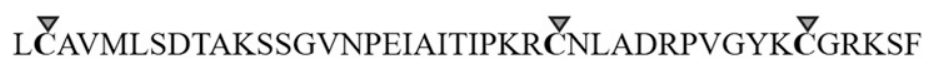

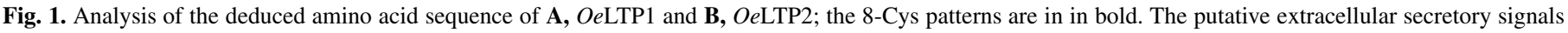
(underlined) are displayed. The hydrophobic cavity of OeLTP1 is highlighted by the light gray box. 
suggesting a good reliability of this biochemical for the association with $X$. fastidiosa infection in olive plant tissues in both leaf petioles and sprigs (Tables 5, 6, and 7). However, to estimate the effective variation of AzA concentration throughout the whole growth season of the tree or to conclude that the accumulation of AzA occurs only in presence of $X$. fastidiosa, further pluriannual tests involving more biotic and abiotic factors are needed.

We speculate that, in both cultivars, AzA could be a mobile signal of $X$. fastidiosa infection which requires an LTP for its activity, as reported for other plant species (Cecchini et al. 2015; Shine et al. in press). The two identified genes, named OeLTP 1 and OeLTP2, and their protein sequence analysis showed that both proteins have specific domains commonly associated with the LTP family, to which the previously described AZI1 and DIR1 belong, and which are two key components of AzA activity in the SAR pathway (Cameron et al. 2016; Cecchini et al. 2015; Champigny et al. 2013; $\mathrm{Yu}$ et al. 2013). SAR provides long-lasting and broad-spectrum protection at the whole-plant level against virulent pathogens ( $\mathrm{Fu}$ and Dong 2013) and it has been reported to confer fitness under conditions of high disease pressure (Traw et al. 2007). The identifying genes code for two proteins that are both characterized by a consensus motif of eight cysteine residues commonly associated with LTPs, which can be divided into multigenic families LTP1 and LTP2. In addition, the OeLTP1 protein presents a central hydrophobic cavity, determined by training four disulphide bridges, which can bind long fatty acid chains (Cecchini et al. 2015; Lascombe et al. 2008; Yeats and Rose 2008) (Figs. 1 and 2). OeLTP1 is clearly classified as an $n s$ LTP1 type, with a high similarity to the previously described LTP type 1 sequences in pepper, tomato, cotton, and Arabidopsis, as confirmed by the phylogenetic analysis. On the other hand, OeLPT 2 is part of the LTP2 family and is grouped with NtDIR1 and $A t \mathrm{DIR} 1$, a protein required for the production or transport of SAR long-distance signals in Arabidopsis (Cameron et al. 2016).

In our study, the expression level of OeLTP1 and OeLTP2 in petiole samples showed a significant upregulation in samples positive to $X$. fastidiosa, with some differences among cultivars. In particular, in the susceptible Cellina di Nardò, the two transcripts were not detectable by real-time PCR up to $40 C_{t}$, suggesting a very low expression level, whereas $C_{t}$ values were much lower in positive samples of this cultivar than those belonging to Leccino. Although there are many reports about the role of LTPs in many physiological functions, we believe that our study is the first report on the effects caused by $X$. fastidiosa (or other pathogens) to O. europaea LTP gene expression. Previous studies in wheat showed the regulation of LTP transcripts in response to a pathogen, suggesting a key role in the early stages of pathogenesis of LTP in relation to the transport of signaling molecules (Safi et al. 2015; Wu et al. 2014). Similarly, in Capsicum annum, three genes coding LTP were up regulated by pathogen infection (Jung et al. 2003).

Conclusions. There are few metabolomic studies of plantpathogen interactions and relative AzA production. Much of what is known about the metabolic intermediates involved in plant responses to pathogens in vegetative tissues comes from studies in Arabidopsis. Although further trials are needed to prove the robustness of our data (i.e., artificial infections, different sampling seasons, and evaluations of other cultivars), we propose a correlation between the accumulation of AzA and $X$. fastidiosa infection in olive trees, underlined by the six- to sevenfold increase of the compound in positive plants compared with the control. The upregulation of two genes encoding LTPs also suggest this correlation. Furthermore, analyzing the microbiome of the tissues of $X f$-p and $X f$-n samples (for example, throughout next-generation sequencing analysis) would be useful to demonstrate that the amount of AzA in the tested samples varies exclusively in relation to the presence or absence of $X$. fastidiosa, excluding differences due to other biotic factors.

However, as with other biochemical based tests, the quantification of AzA as a diagnostic method involves an indirect determination of the pathogen. Thus, the results derived from the quantification of AzA cannot be used to confirm the presence of $X$. fastidiosa which, on the other hand, can be definitively assessed by traditional methods. Despite this limitation, our approach represents a rapid and low-cost screening method for the large-scale monitoring of an erratically distributed pathogen.

\section{LITERATURE CITED}

Ádám, A. L., Nagy, Z. Á., Kátay, G., Mergenthaler, E., and Viczián, O. 2018. Signals of systemic immunity in plants: Progress and open questions. Int. J. Mol. Sci. 19:1146.

Alagna, F., Mariotti, R., Panara, F., Caporali, S., Urbani, S., Veneziani, G., Esposto, S., Taticchi, A., Rosati, A., Rao, R., Perrotta, G., Servili, M., and Baldoni, L. 2012. Olive phenolic compounds: Metabolic and transcriptional profiling during fruit development. BMC Plant Biol. 12:162.

Almeida, R. P. P. 2016. Can Apulia's olive trees be saved? Science 353: 346-348.

Aroca, A., Raposo, R., and Lunello, P. 2008. A biomarker for the identification of four Phaeoacremonium species using the $\beta$-tubulin gene as the target sequence. Appl. Microbiol. Biotechnol. 80:1131-1140.

Bilodeau, G. J., Koike, S. T., Uribe, P., and Martin, F. N. 2012. Development of an assay for rapid detection and quantification of Verticillium dahliae in soil. Phytopathology 102:331-343.

Camañes, G., Scalschi, L., Vicedo, B., Gonzàlez-Bosch, C., and Garcìa-Agustìn, P. 2015. An untargeted global metabolomic analysis reveals the biochemical changes underlying basal resistance and priming in Solanum lycopersicum, and identifies 1-methyltryptophan as a metabolite involved in plant responses to Botrytis cinerea and Pseudomonas syringae. Plant J. 84:125-139.

Cameron, R. K., Carella, P., Isaacs, M., Champigny, M., Merl-Pham, J., Dey, S., and Vlot, A. C. 2016. Using DIR1 to investigate long-distance signal movement during systemic acquired resistance. Can. J. Plant Pathol. 38: 19-24.

Carlucci, A., Lops, F., Cibelli, F., and Raimondo, M. L. 2015. Phaeoacremonium species associated with olive wilt and decline in southern Italy. Eur. J. Plant Pathol. 141:717-729.

Cecchini, N. M., Steffes, K., Schläppi, M. R., Gifford, A. N., and Greenberg, J. T. 2015. Arabidopsis AZI1 family proteins mediate signal mobilization for systemic defence priming. Nat. Commun. 6: Article 7658.

Champigny, M. J., Isaacs, M., Carella, P., Faubert, J., Fobert, P. R., and Cameron, R. K. 2013. Long distance movement of DIR1 and investigation of the role of DIR1-like during systemic acquired resistance in Arabidopsis. Front. Plant Sci. 4:230.

Chiriacò, M. S., Luvisi, A., Primiceri, E., Sabella, E., De Bellis, L., and Maruccio, G. 2018. Development of a lab-on-a-chip method for rapid assay of Xylella fastidiosa subsp. pauca strain CoDiRO. Sci. Rep. 8: Article 7376.

Coletta-Filho, H. D., Francisco, C. S., Lopes, J. R., Muller, C., and Almeida, R. P. P. 2017. Homologous recombination and Xylella fastidiosa hostpathogen associations in South America. Phytopathology 107:305-312.

Coletta-Filho, H. D., Francisco, C. S., Spotti-Lopes, J. R., De Oliveira, A. F., and De Oliveira da Silva, L. F. 2016. First report of olive leaf scorch in Brazil associated with Xylella fastidiosa subs. pauca. Phytopathol. Mediterr. 55:130-135.

Drenth, A., Wagels, G., Smith, B., Sendall, B., O'Dwyer, C., Irvine, G., and Irwin, J. A. G. 2006. Development of a DNA-based method for detection and identification of Phytophthora species. Australas. Plant Pathol. 35: 147-159.

Edwards, K., Johnstone, C., and Thompson, C. 1991. A simple and rapid method for the preparation of plant genomic DNA for PCR analysis. Nucleic Acids Res. 19:1349.

Elkacmi, R., Kamil, N., Bennajah, M., and Kitane, S. 2016. Extraction of oleic acid from Moroccan olive mill wastewater. BioMed Res. Int. 2016: Article 1397852.

Fu, Z. Q., and Dong, X. 2013. Systemic acquired resistance: Turning local infection into global defense. Annu. Rev. Plant Biol. 64:839-863.

Garrido, C., Carbú, M., Fernández-Acero, F. J., Boonha, N., Colyer, A., Cantoral, J. M., and Budge, G. 2009. Development of protocols for detection of Colletotrichum acutatum and monitoring of strawberry anthracnose using real-time PCR. Plant Pathol. 58:43-51.

Giampetruzzi, A., Morelli, M., Saponari, M., Loconsole, G., Chiumenti, M., Boscia, D., Savino, V. N., Martelli, G. P., and Saldarelli, P. 2016. Transcriptome profiling of two olive cultivars in response to infection by the CoDiRO strain of Xylella fastidiosa subsp. pauca. BMC Genomics 17: 475.

Giampetruzzi, A., Saponari, M., Almeida, R. P. P., Essakhi, S., Boscia, D., Loconsole, G., and Saldarelli, P. 2017. Complete genome sequence of the 
olive-infecting strain Xylella fastidiosa subsp. pauca De Donno. Genome Announc. 5:e00569-e17.

Godard, A., De Caro, P., Thiebaud-Roux, S., Vedrenne, E., and Mouloungui, Z. 2013. New environmentally friendly oxidative scission of oleic acid into azelaic acid and pelargonic acid. J. Am. Oil Chem. Soc. 90:133-140.

Harper, S. J., Ward, L. I., and Clover, G. R. G. 2010. Development of LAMP and QPCR methods for the rapid detection of Xylella fastidiosa for quarantine and field applications. Phytopathology 100:1282-1288.

Jung, H. W., Kim, W., and Hwang, B. K. 2003. Three pathogen-inducible genes encoding lipid transfer protein from pepper are differentially activated by pathogens, abiotic and environmental stresses. Plant Cell Environ. 26:915-928

Jung, H. W., Tschaplinski, T. J., Wang, L., Glazebrook, J., and Greenberg, J. T. 2009. Priming in systemic plant immunity. Science 324:89-91.

Kachroo, A., and Robin, G. P. 2013. Systemic signaling during plant defense. Curr. Opin. Plant Biol. 16:527-533.

Kumar, S., Stecher, G., and Tamura, K. 2016. MEGA7: Molecular evolutionary genetics analysis version 7.0 for bigger datasets. Mol. Biol. Evol. $33: 1870-1874$

Lascombe, M. B., Bakan, B., Buhot, N., Marion, D., Blein, J. P., Larue, V., Lamb, C., and Prange, T. 2008. The structure of "defective in induced resistance" protein of Arabidopsis thaliana, DIR1, reveals a new type of lipid transfer protein. Protein Sci. 17:1522-1530.

Luvisi, A., Aprile, A., Sabella, E., Vergine, M., Nicolì, F., Nutricati, E., Miceli, A., Negro, C., and De Bellis, L. 2017a. Xylella fastidiosa subsp. pauca (CoDiRO strain) infection in four olive (Olea europaea L.) cultivars: Profile of phenolic compounds in leaves and progression of leaf scorch symptoms. Phytopathol. Mediterr. 56:259-273.

Luvisi, A., Nicolì, F., and De Bellis, L. 2017b. Sustainable management of plant quarantine pests: The case of olive quick decline syndrome. Sustainability 9:659.

Machado, M., Felizardo, C., Fernandes-Silva, A. A., Nunes, F. M., and Barros, A. 2013. Polyphenolic compounds, antioxidant activity and Lphenylalanine ammonia-lyase activity during ripening of olive cv. "Cobrançosa" under different irrigation regimes. Food Res. Int. 51:412-421.

Maddox, C. E., Laur, L. M., and Tian, L. 2010. Antibacterial activity of phenolic compounds against the phytopathogen Xylella fastidiosa. Curr. Microbiol. 60:53-58.

Martelli, G. P. 2016. The current status of the quick decline syndrome of olive in southern Italy. Phytoparasitica 44:1-10.

Martín, M. T., Cobos, R., Martín, L., and López-Enríquez, L. 2012. qPCR detection of Phaeomoniella chlamydospora and Phaeoacremonium aleophilum. Appl. Environ. Microbiol. 78:3985-3991.

Martín, M. T., Cuesta, M. J., and Martín, L. 2014. Development of SCAR primers for PCR assay to detect Diplodia seriata. Int. Scholarly Res. Not. 2014: Article 824106

Martinelli, F., Scalenghe, R., Davino, S., Panno, S., Scuderi, G., Ruisi, P., Villa, P., Stroppiana, D., Boschetti, M., Goulart, L. R., Davis, C. E., and Dandekar, A. M. 2015. Advanced methods of plant disease detection. A review. Agron. Sustain. Dev. 35:1-25.

Nagy, Z. Á., Kátay, G., Gullner, G., Király, L., and Ádám, A. L. 2017. Azelaic acid accumulates in phloem exudates of TMV-infected tobacco leaves, but its application does not induce local or systemic resistance against selected viral and bacterial pathogens. Acta Physiol. Plant. 39:9.

Parnell, S., Gottwald, T. R., Gilks, W. R., and van den Bosch, F. 2012. Estimating the incidence of an epidemic when it is first discovered and the design of early detection monitoring. J. Theor. Biol. 305:30-36.

Romanazzi, G., Murolo, S., Pizzichini, L., and Nardi, S. 2009. Esca in young and mature vineyards, and molecular diagnosis of the associated fungi. Eur. J. Plant Pathol. 125:277-290.

Sabella, E., Luvisi, A., Aprile, A., Negro, C., Vergine, M., Nicolì, F., Miceli, A., and De Bellis, L. 2018. Xylella fastidiosa induces differential expression of lignification related-genes and lignin accumulation in tolerant olive trees cv. Leccino. J. Plant Physiol. 220:60-68.

Safi, H., Saibi, W., Alaoui, M. M., Hmyene, A., Masmoudi, K., Hanin, M., and Brini, F. 2015. A wheat lipid transfer protein (TdLTP4) promotes tolerance to abiotic and biotic stress in Arabidopsis thaliana. Plant Physiol. Biochem. 89:64-75.

Saponari, M., Boscia, D., Altamura, G., Loconsole, G., Zicca, S., D’Attoma, G., Morelli, M., Palmisano, F., Saponari, A., Tavano, D., Savino, V. N., Dongiovanni, C., and Martelli, G. P. 2017. Isolation and pathogenicity of Xylella fastidiosa associated to the olive quick decline syndrome in southern Italy. Sci. Rep. 7: Article17723.

Saponari, M., Boscia, D., Nigro, F., and Martelli, G. P. 2013. Identification of DNA sequences related to Xylella fastidiosa in oleander, almond and olive trees exhibiting leaf scorch symptoms in Apulia (southern Italy). J. Plant Pathol. 95:668.

Servili, M., Esposto, S., Lodolini, E., Selvaggini, R., Taticchi, A., Urbani, S., Montedoro, G., Serravalle, M., and Gucci, R. 2007. Irrigation effects on quality, phenolic composition, and selected volatiles of virgin olive oils cv. Leccino. J. Agric. Food Chem. 55:6609-6618.

Shah, J. 2009. Plants under attack: Systemic signals in defence. Curr. Opin. Plant Biol. 12:459-464.

Shine, M. B., Xiao, X., Kachroo, P., and Kachroo, A. Signaling mechanisms underlying systemic acquired resistance to microbial pathogens. Plant Sci. In press. doi.org/10.1016/j.plantsci.2018.01.001 an

Siebers, M., Brands, M., Wewer, V., Duan, Y., Hölzl, G., and Dörmann, P. 2016. Lipids in plant-microbe interactions. Biochim. Biophys. Acta 1861: 1379-1395.

Stokstad, E. 2015. Italy's olives under siege. Science 348:620.

Tenenboim, H., and Brotman, Y. 2016. Omic relief for the biotically stressed: Metabolomics of plant biotic interactions. Trends Plant Sci. 21:781-791.

Traw, M. B., Kniskern, J. M., and Bergelson, J. 2007. SAR increases fitness of Arabidopsis thaliana in the presence of natural bacterial pathogens. Evolution 61:2444-2449.

Upchurch, R. G. 2008. Fatty acid unsaturation, mobilization, and regulation in the response of plants to stress. Biotechnol. Lett. 30:967-977.

Walley, J. W., Kliebenstein, D. J., Bostock, R. M., and Dehesh, K. 2013. Fatty acids and early detection of pathogens. Curr. Opin. Plant Biol. 16: 520-526.

Wallis, C. M., and Chen, J. 2012. Grapevine phenolic compounds in xylem sap and tissues are significantly altered during infection by Xylella fastidiosa. Phytopathology 102:816-826.

Wu, S., Wang, H., Yang, Z., and Kong, L. 2014. Expression comparisons of pathogenesis-related (PR) genes in wheat in response to infection/ infestation by Fusarium, Yellow dwarf virus (YDV) aphid-transmitted and Hessian fly. J. Integr. Agric. 13:926-936.

Yeats, T. H., and Rose, J. K. C. 2008. The biochemistry and biology of extra cellular plant lipid-transfer proteins(LTPs). Protein Sci. 17:191-198.

Yu, K., Soares, J. M., Mandal, M. K., Wang, C., Chanda, B., Gifford, A. N., Fowler, J. S., Navarre, D., Kachroo, A., and Kachroo, P. 2013. A feedback regulatory loop between G3P and lipid transfer proteins DIR1 and AZI1 mediates azelaic-acid-induced systemic immunity. Cell Rep. 3: 1266-1278.

Zarco-Tejada, P. J., Camino, C., Beck, P. S. A., Calderon, R., Hornero, A., Hernández-Clemente, R., Kattenborn, T., Montes-Borrego, M., Susca, L., Morelli, M., Gonzalez-Dugo, V., North, P. R. J., Landa, B. B., Boscia, D., Saponari, M., and Navas-Cortes, J. A. 2018. Previsual symptoms of Xylella fastidiosa infection revealed in spectral plant-trait alterations. Nat. Plants 4 : 432-439.

Zoeller, M., Stingl, N., Krischke, M., Fekete, A., Waller, F., Berger, S., and Mueller, M. J. 2012. Lipid profiling of the Arabidopsis hypersensitive response reveals specific lipid peroxidation and fragmentation processes: Biogenesis of pimelic and azelaic acid. Plant Physiol. 160:365-378. 